\title{
Efforts to Develop the Reading Interest of the People from Children in Singapore Libraries
}

\author{
Xiuqi Gong \\ University of Shanghai for Science and Technology Library, Shanghai, China \\ Email address: \\ 2509845424@qq.com \\ To cite this article: \\ Xiuqi Gong. Efforts to Develop the Reading Interest of the People from Children in Singapore Libraries. Science Journal of Education. \\ Vol. 4, No. 6, 2016, pp. 198-205. doi: 10.11648/j.sjedu.20160406.16
}

Received: June 30, 2016; Accepted: December 19, 2016; Published: December 29, 2016

\begin{abstract}
This paper introduces some successful efforts in Singapore libraries in developing the reading interest of children and adolescents, including reading promotion activities organized by Singapore public libraries, librarians' training of children libraries, children's books selection, and the collection development of children' libraries. This paper shows the studies from both theory and practice and hopes to provide some reference and enlightenment for the cultivation of reading interest for children and adolescents.
\end{abstract}

Keywords: Singapore Library, Reading Promotion, Children

\section{Introduction}

In the description on the "Mission of the Public Library" from "Public Library Manifesto" of United Nations Educational, scientific and Cultural Organization in the 1994, the first rule is to develop and enhance children's reading habits [1]. The public library is the core of children's reading education and guidance. There is no other such place which can store the complete knowledge of children's growth, education, and so on. The libraries can meet the children's desire for knowledge and in turn affects the writing and publishing of juvenile books. At the same time, the libraries have imposed the influence for the family and community education, even the overall quality of the whole nation.

Since 1995, in a short period of more than 10 years, Singapore Library became one of the best libraries in the world. It shows the advanced library operation mode of a developed country and creates the "Singapore experience" recognized by the international library community [2]. The Singapore National Library has taken many effective measures to develop the reading interests from the children. People can use the information service provided by the libraries. The quality of the population has been improved by the way of lifelong learning, which enhances the overall national competitiveness and make Singapore as a learning nation.

Since its establishment in 1995, Singapore National Library system has been built into in a world-class, highly efficient and convenient library service system including a National Library, three large regional libraries, 24 public libraries, 31 government agency libraries and the school libraries [3]. Large regional libraries are usually located in the convenient places around the subway stations. The Community libraries are usually located not more than 200 meters from the nearest residential community. Some of the libraries are also located in the business centers and downtown areas. The libraries simplify the procedures of borrowing and returning books with the use of the high-technological ways. The good reading environment make people feel enjoyable when they are reading books in the libraries. Each large regional library has provided special services dedicated to children and youth. There are also more than 10 community children's libraries as the fun game field outside the schools.

\section{Several Famous Libraries for Children in Singapore}

Singapore library firmly believes that good habits must be developed from the children in order to attract young people and retain the future of the library. It is necessary for the library to adapt to the physical and psychological 
characteristics of children and adolescents. The biggest characteristic of teenagers is lively, curious and of plasticity. But the library is a public place known for quietness. How to deal with the static and dynamic is a difficult problem for the library to attract readers. Children can still move and play within the library in Singapore. In fact, children play quietly, do not disturb others. Static and dynamic are in a harmony in the Singapore Libraries. In the libraries, students can use the library's quiet environment to do homework or prepare exams instead of using the resources of the library. The libraries are located in the bustling shopping centers. Many residents take the children to read there when going out with the family for entertainment. Students usually go to the library to do homework after school.

\subsection{Jurong Regional Library}

Jurong Regional Library is the largest regional library established by the Singapore National Library. It is the first library to provide services specifically for youth in Singapore. It was founded by young people to create a dynamic environment for young people to express themselves, realize the dream, and explore the future together.

The library goes deep into the community to conduct in-depth investigation among young people about the problem that young people are not willing to go to the library. After analyzing the reasons for the boring of the library, the young people are invited to participate in the environmental design of the library. Teens Library Service department is located on the fourth floor of the library with an area of about 1200 square meters. The environment is very comfortable. There is a relatively closed space for a small gathering for young readers. The library specifically set up a wall of graffiti, comic wall and so on for young people to display their drawing, and add the popular music information display area. All of these methods are well received by young readers. All these are designed together with the young volunteers during the construction of the library.

The library collects various styles of comics and illustrated novels, the most popular animation works and mainstream writers all can be found here. There is also a Children Advisory \& Resource Centre, children, parents, educators and caregivers can choose and borrow the appropriate reading materials and resources here. There is also a special children's Resource Center dedicated to provide the school's project resources, as well as the reference materials of children's literature and children's development of the psychology. The collection of Children's Resource Center selects the most excellent books for all ages including the classic and popular stories, award-winning works representing folk stories, fairy tales, and put a special emphasis on the children's books about Asia.

The basement of the library is specially created for young children, many of which appear to be only a few months old baby being held by her mother or sitting in a baby carriage to be pushed into. There are even special books designed for the baby biting and tearing. There is a place to hang the sign of "read aloud", the mother can read the books to the baby here.

\subsection{Woodland Regional Library}

Singapore Woodland Regional Library is Singapore's largest public library covering an area of 11100 square meters [4]. It provides various reference service for both adults and children. The concept of Services Children department is to cultivate good reading habits from the childhood. Team experts are committed to providing the appropriate reading materials and resources for parents and educators. The overall design of the children's library is like a reading Park which provides the reading environment for children and their caregivers.

In Singapore Woodlands Regional Library, children can listen to parents in fairy tales under the trees, Young people can enjoy the reading while listening to the music before the window, outside the window is the waterfall flying straight down. There is the coffee shop near the gate of the library.

\subsection{Bishan Public Library}

In Bishan Public Library, children's special reading area is located in the basement. The shape is like an underground cave, so as to avoid the interference of noise from the upper area, and create the best learning and playing conditions for children. From the curiosity of the children and the psychological and reading habits, the seats are designed into a petal pattern with a lively candy color. The ground is decorated with a dynamic line design. In this interesting environment, the children can enjoy their imagination and feel the joy of reading.

\subsection{Singapore National Library}

Singapore National Library is one of the largest and most advanced libraries in Southeast Asia. It was officially opened in 1960 and rebuilt in 2005. The new building is located in the center of the golden location of Vitoria Avenue 100, consists of two 16-storey building, each floor has a bridge connection [5]. Although the library is located in the downtown, but has no noisy feeling, it creates and provides a beautiful reading space and environment for the readers.

As a very solemn national library, one of the notable features is to promote children's reading promotion, exclusively opens up a free play ground for the children. There are colorful children's books for children to select and read. Children can put the book on the ground, sitting, lying, or reading, and completely immerse in the story of the book.

In 2013, Singapore National Library built the first Children library with the theme of green environment in the world, called "The Tree House". The main decorations are made from recycled wood, PVC pipes and plastic bottles, and the library equipped with $70 \%$ recycled materials and LED energy saving lamps. This "tree house" is located in the children's area of the National Library basement with an area of 500 square meters. There are 70000 books on the theme of green environment [6]. It aims to let the children familiar with the practice of green environment, to cultivate children's awareness of environmental protection, so as to create a new generation of natural lovers. In the design process of the 
library, the organizer also adopted some small readers' and parents' opinions in order to build a truly suitable library for children.

\section{Reading Promotion Activities for Children and Adolescents in Singapore Library}

More than three thousand activities for children and adolescents are held by libraries every year, which stimulates the interest of readers, so as to promote the readers to use the libraries more frequently and more actively.

Among them, the following activities are well known.

\subsection{Born to Read, Read to Bond}

In order to encourage national lifelong learning and reading, Singapore National Library Board implemented "Born to Read, Read to Bond" project. The project was led by Singapore National Library Board in cooperation with Ministry of Community Development and Sports (MCDS). This project expected that the people have the habit of reading from the childhood, and took this trend into every family.

This plan aimed to encourage reading for young people and support the life-long reading, promote reading as a means to facilitate the bridging process between parent and children (including new-borns), build the self-esteem and positive values to the child through reading activities.

The program included the membership system for the children from the birth to three years old, reading programs and conversations between parents and children's, etc. The project lasted from November 2001 to December 2002, and nine Singapore large hospitals participated in this project. The hospitals had about fifty thousand mothers of newborn babies to accept a one-stop service [7]. Organizers distributed them a reading package including guidance about how to be parents, raising children and a series of related reference books, a guidance of library and a library membership registration form. If the parents of newborn babies registered the library membership for their children, the libraries would design a unique membership card. The baby could borrow four books with this membership card at one time. Children also received a reading bag containing a list on the books of children's parenting, toys and baby products. NLB hosted a series of reading programs throughout the year, including "read to me" (3 years old), "read with me" (4-6 years old) and "read together" (7 years old). These projects were designed to increase the parent-child relationship and develop the reading habit. The hospitals and the public libraries also gave public lectures about parenting and developing children's reading habits.

\subsection{Asian Children's Festival}

Singapore National Library held an annual reading festival of Asian children's Asian (ACF) from 2000. The event received good response with the increasing participants year by year. 4-12 years old children are the target group for this event, and there are some activities organized specifically for children with special needs and disabilities [7]. The festival aims to promote an Asia-Pacific identity and broaden the minds and experience of children, develop an awareness of common Asian-Pacific traditions and culture through learning, education and developing creative programs for children, stimulate children's writing and publishing for children, encourage and promote the art of storytelling, encourage and promote the art of storytelling.

This is a very large scale activity with different themes and focuses every year, usually including Asian Storytelling Carnival, Asian Children's Expo (ACE), Asian Children's Writers and Illustrators Conference, Asian Congress of Storyteller, Children's Drama Fiesta and Asian Children's Film Festival. Storytelling occupied the largest proportion in ACF, more than half of the activities were related to it. Organizers believed that reading and storytelling played an important role in the growth of children since they learn the wisdom of life from literature, art, culture, tradition and legends and other literary and artistic works. Asian Storytelling Carnival (ASC) is a storytelling activity across the country. Many famous storytellers and well-known artists from around the world and the local were invited to participate. The venue for ASC included each library, subway and bustling shopping center. Children learned more on Asian culture, content, traditions and values in a pleasant atmosphere.

Asian children's Expo (ACE) was a 3-4 days' exhibition to provide a face-to-face communication platform with the target audience in the field of children's education and entertainment. Children and parents can participate in various activities such as crafts, games, performances, seminars. The activity mixed the game and the learning together, thus children learned the culture of Asia in the creative and fun environment. For example, ACE included activities including the interactive art appreciation courses, and practice of art productions, craft activities, taste of Turkey candy and tea, pottery and clay making skills, performances between actors and children, exciting drama and puppet shows, fun puzzles and sports games etc. in 2004.

Asian Children's Writers and Illustrators Conference invited the award-winning writers, famous publishers, experts in children's literature and publishing, and artists from different regions to share expertise and experience on the Asian content development.

Asian Children's Festival acted as the catalyst for the development of Asian children's books and media, so that Asian publishers learned a rich variety of traditional culture, and use it as the basis for creating children's stories, rather than simply translating western stories into local languages. The activity also served as a platform to enhance the urgency of Asian books and materials and urge Asian Writers, publishers and artists to publish their work

\subsection{KidsREAD}

In 2004 Singapore National Library Board launched a nationwide reading program named KidsREAD for children. 
It aimed to create collaborative reading program for 4-8 years old children in Singapore, promote reading hobby and develop good reading habit for the children especially from low-income families. It also helped to form values of the ethnic harmony in the young people and improve the life quality of children and families.

The goal was to attract at least 2000 children aged from 4 to 8 years in three years, especially children from low-income families, and set up 45 reading clubs. Singapore National Library Board recruited and trained volunteers to strengthen their capacity on reading, storytelling and developing activities, and providing services for readers with reading skills toolkit from NLB.

The number of participants had increased from 272 to more than 1600, and the number of clubs increased to 35 in 2006. The number of volunteers rose from 73 in 2004 to 545 in 2012. There were 43 primary schools with KidsREAD club and totally 125 clubs in Singapore. The number of volunteers and students was more than 5000 [7]. Singapore Ministry of education encouraged more elementary schools to participate in KidsREAD.

\subsection{Fathers Reading}

In 2007 Singapore National Library held a national reading activity namely 10000 Fathers Reading! This activity is jointly organized by the Singapore National Library and Centre For Father to encourage fathers to be more involved in the training of children's reading and writing abilities, and strengthen the relationship between father and children. Fathers who participated in the activity obtained a package including recommended books, parent-child reading children's books and reading record card. Father and children exchanged gifts with the stamp printed by the librarian on reading record card.

In 2008, two new programs were introduced to broaden the initiative's outreach, one of which was Read A Story With Your Dad! Book Review that attracted more than 6,000 entries. The Dad! Get Spotted Contest captured 200 photographs of fathers reading to their children at the public libraries which were on display as a photo exhibition at the Woodlands Regional Library. The object was extended to the prospective father, grandfather, uncle and male caregiver / guardian in 2009 and children age range was extended to 12 years old. 15 fathers who support the project activities, love reading and have good reading habits were chosen as reading ambassadors for the first time to inspire more fathers. The fifth activity in 2011 advocated that the loving reading was the best gift that parents could give to their children. The target are the fathers in the industries of aviation, performance, technology and sports. Considering the irregular working time in these industries, libraries supported these fathers and provided resources to encourage them to read the story aloud to the children, and record the feelings while reading with their children together.

\subsection{Quest - First Ever Collectible Card Game}

Many parents know the difficulties of inspiring the children who do not like reading to pick up the book. In June 2009, Singapore National Library launched an innovative reading activities called Quest - First Ever Collectible Card Game which inspired the children who did not like reading to pick up the book through collecting and exchanging the game cards. The library printed the vivid story in the back of the cards. Children read the story and exchanged reading experience with others while collecting and exchanging the game cards. After the first series, the activity successfully attracted more than 70 thousand children to read. As high as 2 million books were borrowed and 1.5 million game cards were exchanged. The investigation taken by the public libraries about children reading interest and habits showed that teenagers especially boys loved collecting game cards, $75 \%$ of game cards were collected and exchanged by boys. It proved that children loved reading comics and fantasy adventure stories.

After the first series was successfully held in 2009, National Library Board launched Quest II in the following year to collect a series of new cards and a story written by a well-known children's librarian. Libraries hoped to attract the children and provide the room for exploring the information and interact with like-minded peers. In addition to collecting the game cards with a touching story, the libraries also designed a children's Cosplay contest, parent-child competition on art coloring and comic seminars. Comic artists shared basic painting skills. "Quest of the Rain Dragon" exhibition also attracted the people. The libraries worked together with more schools and organized the painting competition and the mass lending books to stimulate the reading interest of children, thus prompt them to gain knowledge and happiness during reading.

\subsection{Read It! Singapore}

"Read it! Singapore" is a famous national reading promotion activity in Singapore starting from 2005, which aimed to recommend books for readers and encourage people to read. At the beginning of each year, 12 books in the four official languages were selected by the committee to attract more participants to enhance their reading interests. Reading groups, schools, associations, clubs, education and cultural groups, as well as public or private institutions, etc., could participate in this event. The committee cooperating with the office groups organized the reading guidance meeting and workshops in a large-scale to arrange face-to-face meeting between the writers and the readers in schools, libraries, book clubs, cafes, cafes, clubs, shops, businesses, and even the neighborhood, people club and other appropriate places. They set up a webpage in the Internet for the participants to publish personal views or experience and present the relevant drama, games, movies, exhibitions, reading report essay contest, etc.

Some of these activities were designed especially for children to develop their reading interest and habits from a childhood. For example, READ! Singapore was reaching out to youths in the region with the inaugural "Youth Writers Awards Asia 2010". Organised in partnership with Reader's Digest, this short story writing competition was held in celebration of Singapore hosting the Singapore 2010 Youth 
Olympic Games. Youths at the age of 13 to 17 year olds could submit short stories on the theme of "Dare to Dream: Stories of Imagination, Passion and Sporting Excellence". Winning stories were printed in books to distribute in Singapore at the Youth Olympic Games as part of an effort to promote the national sports. Hope that the region's youth establish a common bond through loving reading. The activity in 2012 with the new theme - "Bridges" expanded to include readers from the age of 7 to 14 . In order to meet the needs of young readers, tNLB enabled students to form a youth book selection committee, including college and junior college students above 12 years old. The selection committee must be the students who love reading and like to communicate and interact with young readers. The committee was responsible for determining the proper books in the four official languages, recommending books for youth, cultivating the love of literature and art, and promoting the reading culture for youth.

\section{Inspiration of Singapore Library's Reading Promotion Activities for Children}

\subsection{Government Supporting, Political Participation}

The Singapore government realizes the important role of Library in the information society very early. The library is not only the pure government culture business, but also improves the quality of national culture and promotes the sustained economic growth. Government treats the library network construction as the national basic infrastructure and provides sufficient financial support to libraries. Singapore children's reading activities organized by Libraries were all carried out under the support of the government. Government officials are invited in every opening ceremony of the reading activity in Singapore. For example, Asian Children's Festival 2002 invited Lee Boon Yang Minister, for Manpower Dr. 10000 Fathers Reading 2007 invited Gan Kim Yong Minister, of State for Education and Manpower Mr. KidsREAD 2004 invited the deputy prime minister and finance Lee Lsien Long.

The government's strong supporting makes the public aware of government's orientation for reading. Government officials' participating makes the readers fully realize the government' attention to children's reading. These greatly increases the appeal of reading activities and made promotion activity full of vitality and longevity

\subsection{Cooperative Objects}

The libraries usually organize reading promotion activities with some agencies including government departments, non-governmental organizations, and a variety of media and enterprises. By integrating the strength of the library, education, publishing industry, media and businesses it extensively propagandized the importance of reading, stimulated the readers' reading interest, and promoted the library's collections and services.

For example, ACF 2002 was organized in partnership with
23 organizations including the National Arts Council, Singapore Film Commission, the Singapore Film Society, I-Theatre, National Book Development Council of Singapore, NTUC Childcare, NTUC Club, Singapore Reading and Literary Society and Times International Publishing, Mattel etc. The steering committee of KISREAD includes the five self-help groups, namely the Association of Muslim Professionals (AMP), Chinese Development Assistance Council (CDAC), Singapore Indian Development Association (SINDA), the Eurasian Association, Singapore (EA) and Yayasan MENDAKI. The organizers of 2001 Born to Read thanked Dumex, Johnson \& Johnson, Motherhood magazine and Tumble Tots for their enthusiastic support of the project. In 2009, 10000 Fathers Reading organized by the NLB and Action Party Community Foundation (PCF) kindergarten to attract a total of 400 PCF kindergarten, primary school and institutions. The annual ACF attracted a large number of Singapore bookstores and publishers.

A wide range of partners to join strengthened the organizational power of the activities, increased the number of audience, and enhanced the influence of activities.

\subsection{Participating in a Simple and Convenient Way}

Each activity was easy to participate without cumbersome procedures. The timings of activities were usually flexibly arranged on which the readers can freely choose. Locations were maybe near the community library, in the school, subway, even at children's own homes. All activities were free for charge, and the organizers usually provided the kits and rewards to participants.

For example, Asian children's Festival usually lasted for ten days and was arranged within the school holidays at the libraries and schools, so that more children can have more time to participate in. Every reader was encouraged to tell a story to a friend, relative or a colleague in NLB. Readers who want to participate in activities just need to go to any library nearby and fill out a registration form. All the participants got a book as a gift. NLB even encourages people to build their own story club. "Dragon adventure" of Quest II card game activities opened the website to provide more illustrations and content to Dragon fans to view the latest reading promotion activities and know the related matches conveniently and quickly. Children in KidsREAD can easily go to the nearby secondary school or junior college to read aloud or tell a story under the guidance of brothers or sisters as volunteers

\subsection{Good Persistence}

Each library's reading activities were systematic and long-term planning, not like a carnival. After the boom back, reading activities were not stagnant, but continued to play a persistent reading guiding role.

10,000 Fathers Reading! was held a total of five times from 2007 to 2011. KidsREAD held three times from 2004 to 2006. Singapore National Library recruited volunteers all year round who were required to serve the young readers once a week at least in half a year to help readers to develop a good habit of 
reading from childhood.

The results of long-term reading promotion activities were to form a solid foundation of reading consciousness and promote to the whole country, as well as every reader. The reading activities had been widely recognized by the public, so that the public better understood the library's efforts and goals to promote the activities for children. Therefore the children have gradually become the solid reader group of the libraries.

\subsection{Teamed up with Sponsors}

Many of the library activities were organized by libraries and enterprises together. The enterprises were willing to participate in the activities to support the cultural undertakings on the one hand, and also promote themselves on the other hand. The libraries can get the strong economic supporting from enterprises and better organize reading activities. Thus, libraries became the bridge of connecting business and community to form a good interactive situation of our culture and commerce industries.

For example, the three-year program of KISREAD was supported by the Ministry of Community Development and Sports. The main sponsor was Singapore Pools (Private) Limited. Other sponsors included Popular Book Co (Pte) Ltd, Pansing International Library Services Pte Ltd, and Books and More Pte Ltd.

In the library website, we often found the logo or mark of the sponsors. On the one hand, it let the reader felt warm to know where the prizes come from. On the other hand it brought some publicity for sponsors to promote the long-term cooperation between the sponsors and the libraries.

\subsection{Focus on Promotion of Activities}

Each reading activity was promoted in a variety of rich and colorful way to the public. For example, the organizer designed a special LOGO for activities, put up advertisements at the bus stops and MRT stops with the great flow of people, or printed posters on the taxis. Cooperating with radio and newspaper was a very good approach to promote the activity to publicity. A lot of news on the library's reading activities were published in Singapore's two major newspapers, "Lianhe Zaobao" and "STRAITS TIMES" [8]. There were nearly 1000 reports about the Singapore National Library Board on these two newspapers in 2006 according to statistics. Library also established a special website to interact with readers, so that the annual reading activities, especially ACF, had become a great event for the children and parents. NLB invited a number of well-known artists, comedy actors and news anchors and so on to make short films of NLB's story broadcasting to the public. Librarians usually organized storytelling, crafts and puppet shows for the kids as far as possible in the shopping centers, schools, museums, leisure centers and other busy places to increases the advertising effect and motivate the child's interest.

Readers can pick up all kinds of elaborate brochures, user guide manuals or survey forms whenever and wherever possible in the libraries of Singapore. And the exhibition and video broadcasting in the library provided convenience for readers to use the library and understand various activities. NLB also published a lot of recommended book lists and user manuals free of charge for all activities to readers, some of them were scrambled to collect by readers because of the rich content and beautiful printing.

\subsection{Volunteer Model}

Volunteers are those people or the crowd who engage in public welfare based on the morality, the belief, the responsibility and service consciousness, but not driven by private interests or enforced by law enforcement. Being a volunteer was a kind of glory in Singapore. Singapore libraries introduced the volunteers and established a long-term recruitment and training mechanism for them to develop multi-level volunteer service projects according to the volunteers' own specialty. Volunteers from the general public can engage in the promotion with better authenticity, influence and persuasion. They played a new role for the libraries to improve the service value, just like a bridge between the libraries and the juvenile readers to pull in the distance between them and increase the power of librarians.

Singapore's community children's reading clubs were jointly established by the National Library Board and civil society organizations and, sponsored by enterprises. Children can listen to the volunteers who served as children's reading guiders to tell the story, or put on a short play according to the story from the book, or carry out scientific experiments following steps in science books. If children did not know much about the library, volunteers can help readers understand and learn to use the library facilities and popularize the knowledge of Library Science, so that children can really understand and use of the library more effectively.

\section{The Cultivation of Children's Librarians}

Singapore National Library Board has always paid great attention to the quality development and training of librarians. The librarians are required to have professional qualifications. Singapore Nanyang Technology University has trained a lot of professional talents in the library science in recent years for Singapore. Institute of information and communication in Singapore Nanyang Technology University is always taking a leading position in the whole of Asia. The mission of the Institute is to educate and train professionals and academics in the field of communication and information to serve the community. There are specialized courses on information resources and services for children and adolescents in master's degree so that graduates can be qualified for the job of professional librarians for children and adolescents.

Librarians for children and adolescents should have a strong sense of responsibility and professionalism. They were committed to study how to contact with young people and attract them to participate in various activities organized by the libraries carefully and effectively. Library consultation 
staffs helped readers to query the directory, find a book on the shelf, and even search the answer for a specific question. Librarians not only provided readers with information, the ultimate and the most important was to teach them how to find information, such as bibliography and database. They wanted the reader to feel that they can find everything they need in the library, without fear or inconvenience. Reading guiders in reading activities not only need to study children's books, but also need to understand the psychology of children and master good communication skills, so as to better fulfill the responsibilities of reading guidance [9].

\section{Resources of Children and Adolescents}

The popularization of public libraries and the rich collection of resources were the basis of the reading activities for children and adolescents.

\subsection{Asian Children Collection}

Singapore has a world-class library system. Children's books are the focus of the collection regardless in the National libraries or in the community libraries. The most important department in each library is for children. One of the NLB' feature is the collection of Singapore and South East Asian books. It is worth mentioning that the collection of Asian children's books in National Library has more special features.

Singapore children's literature

- Quality picture books and children's fiction with an Asian setting and/or with Asian characters

- Fiction works with Chinese and Indian Diasporas themes

- Asian culture and customs

- Asian myths and legends

The National Singapore Library collected Asian children's books from 1960s when the need of awareness and understanding for the Asian children's literature increased. The collection was mainly Asian children's literature in four official languages for readers over 13 years old, including Singapore children's literature, Quality picture books and children's fiction with an Asian setting and/or with Asian characters, Fiction works with Chinese and Indian diasporas themes, Asian culture and customs, Asian myths and legends.

Asian children's collection provided valuable materials for the study on children's literature and reading instruction, bibliography. It had played an important role to make the library become the main Asian reference center. In addition to encourage the research on the field of Asian children's literature, these collections had also played a strong role in the National Library Board's annual event, Asian children's Festival, and its related programs, such as Great Singapore Stories、Asian Children's Writers and Illustrators Conference and Asian Children's Expo.

\subsection{Student Reference Center}

After the renovation of the National Library, the library set up an Information Center specifically for students opening to the schools for the first time. Students from junior high schools to colleges can find materials suitable for their interest and the curriculum requirements there. Many junior high schools in Singapore have begun to teach students how to use the library. Schools also encouraged the teachers to take the students to the libraries and teach them how to use the Dewey Decimal Classification to find books on the shelf there.

\subsection{Collection and Selection of Children's Books}

The selecting and cataloging in Singapore Library are completed by the Resource Supply Center. Sometimes part of the work is outsourced to the vendors [10]. In each of the outsourcing vendors, cataloguers and selectors of the books for children were required to be done by the people with specialized and professional knowledge. The reading taste, education level and reading ability of children and teenagers are fully taken into consideration when the books are selected, so that all aspects are well balanced.

Because the number of domestic publications in Singapore is not much, Libraries pay a special attention to the import of foreign books. A lot of Chinese books in the libraries of Singapore are introduced from mainland China. However, due to the lower reading abilities for the children in Singapore comparing with the mainland children, it is necessary to consider the depth of the language of books when imported. At the same time, the durability of the paper and the exquisite degree of design are also factors needed to be considered. It is one of the factors that affects the successful borrowing for children.

Student readers are a large proportion of the readers group for the library. The selection of school books is mainly linked to the school teaching. Books of the subjects that students and teachers are interested in are bought accordingly.

\subsection{Book Recommendation Methods of Singapore Libraries}

The classification of Children's books in Singapore Library is very detailed according to the language and then the age. There are tearproof cloth books for babies, favorite color story books for preschool children, and text books for school-age children.

Each book has a color encoding label in the spine. Different combinations of colors and patterns represent different classifications. The children are attracted by colorful labels at the first sight. The library displays new and good books in a prominent position. In order to attract the attention of young children, some libraries have changed the direction of books and flip them to show the cover to children.

According to the physiological characteristics of children, the bookshelves in children's reading areas are very low. Children can easily take off the books they need. The library provides a free library guide manual with beautifully printed illustrations to parents to instruct parents to assist their children in the proper use of Library facilities.

The circulation desk especially for children is low in the library. Each child has a reading card. Children can knock a seal on his card when he borrows more than 4 books. 15 seals 
can be exchanged for a prize with the library logo. There is one stage designed especially for children under the automatic borrowing and returning machine opening for 24 hours. Child can push books to the machine as long as they are on tiptoe slightly to feel the same sense of accomplishment as adults.

NLB also welcomes schools, learning centers, social organizations, welfare organizations, and community organizations to borrow books in large quantities for their members to promote reading.

\section{Conclusions}

Singapore's public library is a fashion leisure venues designed by Singapore government carefully. The purpose is to arouse people's interest in the books and the public libraries, increase the reading of the whole people, improve the cultural quality of the people, increase interpersonal communication, and create a harmonious multi-ethnic society. As the government continues to increase the investment in the library year after year, and improve constantly the library's reading environment, the people who love reading books are increasing day by day. Now both the native and the foreigner, the library is their first choice for entertainment and leisure. The library is the hub of cultural communication, and a good place for learning, leisure, communication and improving the quality of people for children and adolescents in Singapore.

All activities of the reading promotion organized by the libraries strongly stimulates the enthusiasm of young children's reading, and guides the children to develop the habit and attitude of using library from childhood. The seeds of reading have been planted deeply into the hearts of parents and children, and will have a profound effect on their future.

\section{References}

[1] Yi Zhou, Pei Yu. The Basic Position and Social Roles of Public Library - A Study Based on the 1949, 1972 and 1994 Edition of Public Library Manifesto. Library Tribune, No. 5, 2014, pp. $1-7$.

[2] Li Cui. Corporate Governance of National Library Board Singapore. Library \& Information, No. 3, 2014, pp. 67-73.

[3] Public Library in Singapore National Library Board. http://www.nlb.gov.sg/VisitUs.aspx. [2016-05-01].

[4] Branch Details of Jurong Regional Library. http://www.nlb.gov.sg/VisitUs/BranchDetails/tabid/140/bid/33 8/Default.aspx?branch=Jurong+Regional+Library. [2016-05-02]

[5] National Library / Lee Kong Chian Reference Library. http://www.nlb.gov.sg/VisitUs/BranchDetails/tabid/140/bid/32 9/Default.aspx?branch=National+Library $+\% 2 \mathrm{f}+$ Lee + Kong $+\mathrm{C}$ hian+Reference+Library. [2016-05-02].

[6] Guiju Xu. Space Redesign of Singapore Libraries and Its Enlightenment. Journal of Academic Library, No. 3, 2016, pp. 69-74.

[7] Guiju Xu. Introduction and Analysis of Reading Promotion Activities for Children and Young Adults in U. K., U. S. A., Singapore and Its Enlightenment. Library Journal, No. 4, 2015, pp. 94-102.

[8] Jiali Yuan. From "Read! Singapore" to the Reading Promotion in the University Library of Our Country. New Century Library, No. 7, 2014, pp. 30-33.

[9] Rongna A. A Study on the Internationalization Strategy of Higher Education in Singapore. Asia-Pacific Education, No. 2, 2016, p. 38.

[10] Huiming Sun. Observation and Reflection on Singapore Public Library Service System. Library World, No 3, 2016, pp. 47-50. 